\title{
25 Research Soure \\ Key Features of the Anatomy and Topography of the Sphenoid Sinus in Different Age Periods
}

Merey Aliyeva ( $\square$ aliyevamerey7@gmail.com )

West Kazakhstan Marat Ospanov State Medical University

Mahmoud Farid Mahrous Bathalla

Al Azhar University

Aru Balmagambetova

West Kazakhstan Marat Ospanov State Medical University

Gulmira Zhurabekova

Al-Farabi Kazakh National University

\section{Research Article}

Keywords: Magnetic resonance imaging, sphenoid sinus, pneumatization, internal carotid artery, optic nerve

Posted Date: December 28th, 2020

DOI: https://doi.org/10.21203/rs.3.rs-127603/v1

License: (c) (1) This work is licensed under a Creative Commons Attribution 4.0 International License. Read Full License 


\section{Abstract}

For the period of 2019, magnetic resonance imaging of the head of patients aged 20-71 years was performed. The majority of males have mezocran the shape of the skull, in contrast to females. There was no universal type of pneumatization for both sexes. In young men, the sellar type prevails, but at the age of 60 , this type is 2 times less common and there are no protrusions of the channels of the optic nerves and internal carotid arteries. However, only the protrusion of the internal carotid artery channel is more common in women over 60 years of age than in men. In men, there were no cases of canal protrusion, and $49 \%$ of young women had a depression in the wall of the sphenoid sinus. In men under the age of 60 , the protrusion of the optic nerve channels and internal carotid arteries occurs in approximately the same way as in women over 80 years of age. Due to the variability of the anatomical configuration of the sphenoid sinuses, the impact on access to the cell through the nose can be serious. The surgeon must be aware of these results before surgery in order to reach the cell safely and effectively.

\section{Introduction}

Knowledge of sizes and shapes of skull elements, the structure of sphenoid sinuses, and its interconnection with adjoining structures is necessary to avoid complications when performing surgical endoscopic interventions in chiasmal-sellar region (CSR), which is anatomically difficult to access it [1]. As you know, pneumatization is a presence of air-filled cavities in bones. Probing these cavities is the most affordable, physiologically sparing method of diagnosis and treatment, and require detailed knowledge of pneumatized (air-bearing) bones anatomy. One of such bones is the sphenoid bone, and sphenoid sinus is inside it. Bone resorption is resulting in the formation of sphenoid sinus, the most difficult cavity to access. Sphenoid sinus is separated by a septum with various position, therefore sizes of two sinus cavities are variable [2]. In addition, sphenoid sinus differs in pneumatization type, ranging from its absence to extensive forms [3]. The cusp of sphenoid sinus is located at the end of common nasal passage at the level of middle nasal conch (turbinate) and no higher than $1.5 \mathrm{~cm}$ from choan. Sphenoid stage of operation is started from its detection and expansion. Currently, the transsphenoid approach is the most optimal in neurosurgery for intracellar and cranial pathologies treatment. Due to proximity and anatomical interconnection of sphenoid sinus with other anatomical structures, such as anterior knees of intracavernous segments of internal carotid artery (ICA), optic nerve (ON), there is a high risk of complications during surgery [4-6]. In previous publications the anatomical interconnection was found as range between $11 \%$ and $87 \%$ of cases [7]. In case of extensive pneumatization, these structures can protrude into the sinus air cavity with no separation by bone. And sometimes a thin bone plate can separate them forming a thin-walled canal with prominences in sinus walls, which makes more complications with visibility during surgery [8]. It is necessary to consider optic-carotid pockets (OCP) are formed between bulgings of the ICA and ON canal on both sides, and their severities are very variable. The OCP walls of the are formed by the bony base of the anterior oblique process. Need to have a clear visualization of both OCP to keep midline wound landmark during standard, anterior, lateral extended 
approaches, as well as for ON decompression surgery. In each case, knowledge about the exact sphenoid sinus configuration with its individual characteristics and variations is vital for reducing perioperative complication risks. Thus, the degree and type of sphenoid sinus pneumatization and peculiarities of interconnection between chiasmatic-sellar region (CSR) structures could impact the safety of access to the sphenoid sinus.

The ON position should be taken into account at transphenoidal operations in view of its importance, because topographically it is located in front of sella turcica and very close to anterior tubercles, blocking the passage in both directions between the sellar and suprasellar areas. To prevent iatrogenic damages, some surgeons remove the tubercles and even the wedge-shaped plane, which makes the rehabilitation period worse and/or extends it. A different interconnection between ON intersection and ICA and sphenoid sinus position can lead to amaurosis and bleeding [9]. The risk of blindness is especially high in case of $\mathrm{ON}$ damage inside the sinus, or compression by retrobulbar hematoma results in nerve ischemia with impaired venous outflow. Due to this reason, the surgeon should consider the anatomical features described above and predict complications of performing a lateral canthotomy or decompressing the orbit medial wall if necessary [10]. In addition, reduced visual acuity can be caused by sphenoiditis due to sphenoid sinus anatomical variations predisposing to relapse and, as a result, chronic compression of ON or optic canal, causing ischemia and venous congestion [11].

Bleeding from damaged ICA inside SS, which cannot be controlled during surgery, can be lethal [12]. Unintentional puncture by endoscope or septum avulsion may cause damage of ICA, which requires rapid pressing of ICA to cervical vertebrae. Similarly, the risk factor for intraoperative bleeding may be a combination of such anatomical variations as the Conchal type of pneumatization, narrow intercarotid distance (segments C3, C4, C5), and ICA protrusion [13]. In females, ICA canal protrusion is more by about $1 / 3$ than in males, as well as in females, there are high rates of ICA canal dehiscence (Fig. 1). Therefore, surgeon should be aware of some subtleties and sexual characteristics of transsphenoidal operations in females, determination of positions and variations on preoperative CT is mandatory. According to bibliography, the projection of vessels and nerves adjacent to sinus wall tends to protrude into the cavity as the entire sinus pneumatization increases [14]. Therefore, this study is aimed at studying the features of skull craniometric parameters, the type sphenoid sinus pneumatization, and its practical value in various $\mathrm{ON}$ and ICA positions.

\section{Results}

The data we obtained show that the vast majority of older males (60-80 years old) had mesocrane skull shape, in contrast to females, among whom the frequency of brachycrane skull shape prevails. Among 20-40 years aged males, the highest percentage falls on mesocrane skull form, while in females the frequencies of mesocrane and brachycrane skull forms are relatively the same. In males and females with ages of 40-60 years, mesocrane and brachycranean skull forms are almost half of the total number of cases. An interesting fact was that dolichocranous skull shape is absolutely not found in both males and females of $40-80$ years old age. The skull structure distribution by gender is shown in Figs. 2 and 3 . 
Based on the sphenoid sinus types classification by Ossama \& Guldner, our research revealed that there is no Conchal type (type I) in both genders. In 20-40 age, type III prevailed among males, while type IV has a maximum among females. Types III and IV predominated among males and females of 4060 years old age. In 60-80 years category, type III prevails among females, while males have two times less. Type II is absent among 40-60 aged males and $60-80$ aged females. See Table 1 with $p=0.026$ and Cramer's V $=0.3$.

Table 1

Distribution of SS pneumatization types by gender and age

\begin{tabular}{|c|c|c|c|c|c|}
\hline \multirow[t]{2}{*}{ № } & \multirow[t]{2}{*}{ Type of pneumatization } & \multirow[t]{2}{*}{ Gender } & \multicolumn{3}{|l|}{ Percentage, \% } \\
\hline & & & $20-40$ aged & $40-60$ aged & $60-80$ aged \\
\hline \multirow[t]{2}{*}{1} & \multirow[t]{2}{*}{ Conchal - I type } & $M$ & - & - & - \\
\hline & & $F$ & - & - & - \\
\hline \multirow[t]{2}{*}{2} & \multirow[t]{2}{*}{ Presellar- II type } & M & 16 & - & 40 \\
\hline & & $\mathrm{F}$ & 21 & 28 & - \\
\hline \multirow[t]{2}{*}{3} & \multirow[t]{2}{*}{ Sellar- III type } & M & 47 & 50 & 40 \\
\hline & & $\mathrm{F}$ & 34 & 20 & 80 \\
\hline \multirow[t]{2}{*}{4} & \multirow[t]{2}{*}{ Postsellar - IV type } & M & 37 & 50 & 20 \\
\hline & & $\mathrm{F}$ & 45 & 52 & 20 \\
\hline
\end{tabular}

As per the research of anatomical structures close to SS, it was found that ON and ICA canals form protrusions on the inner surface of the sphenoid sinus sidewall. The protrusion degree was ranged from a slight depression on the lateral wall to a complete "immersion" of canals into the sinus (Fig. 4a, b).

No protrusion of ON and ICA canals were found in $60-80$ years old males in $80 \%$ of cases, while complete absence of protrusion was shown in case of the same age females. However, protrusion of only the ICA canal occurs in $60 \%$ of cases with over 60 years old age females, while the same was in only $20 \%$ with the same age males. There was no case of ON canal protrusion in males, but ON canal gave a protrusion in sphenoid sinus wall in $49 \%$ of $20-40$ years old females. ON and ICA canals protrusion in 20-60 years old males was found in about 30\%, and the same protrusion was found in 60-80 years old females in $40 \%$. See Table 2, $p=0.002$, Cramer's $V=0.4$. 
Table 2

Relation of SS with ON and ICA

\begin{tabular}{|c|c|c|c|c|c|}
\hline \multirow[t]{2}{*}{ № } & \multirow[t]{2}{*}{ Relation of SS with ON and ICA } & \multirow[t]{2}{*}{ Gender } & \multicolumn{3}{|l|}{ Percentage, \% } \\
\hline & & & $20-40$ aged & $40-60$ aged & $60-80$ aged \\
\hline \multirow[t]{2}{*}{1} & \multirow[t]{2}{*}{ No protrusions of ON and ICA canal } & $M$ & 36 & 30 & 80 \\
\hline & & $\mathrm{F}$ & 7 & 40 & - \\
\hline \multirow[t]{2}{*}{2} & \multirow[t]{2}{*}{ Protrusion of ICA canal } & M & 32 & 40 & 20 \\
\hline & & $\mathrm{F}$ & 21 & 32 & 60 \\
\hline \multirow[t]{2}{*}{3} & \multirow[t]{2}{*}{ Bulging of ON canal } & M & - & - & - \\
\hline & & $\mathrm{F}$ & 49 & 8 & - \\
\hline \multirow[t]{2}{*}{4} & \multirow[t]{2}{*}{ Protrusions of ON and ICA canal } & M & 32 & 30 & - \\
\hline & & $\mathrm{F}$ & 21 & 20 & 40 \\
\hline
\end{tabular}

\section{Discussion}

The sphenoid sinus can be seen in computed tomography (CT) as early as 2 years old age and is usually fully grown by the age of 14 [23]. The direction of pneumatization is usually anteroposteriorly. However, the actual degree of pneumatization varies greatly for each person. According to M. V. Tvardovskaya [24], the skull length decreases after 60 years, and for females, this age is after 40 years. The cranial index in females increases after 50 years, i.e. there is a shift towards brachycrania. The cranial index of males changes significantly as they getting older. It was found that 25-60 years old males and 23-55 years old females (of mature age) have a certain range of differences in the parameters we studied. V. A. Pavlov notes that with age, both males and females have a dolichocephalic head shape less common than meso - and brachycephalic ones [25]. Hammer and Radberg (1961) [26], who described three sphenoid sinus anatomical types such as Conchal, presellar, and sellar, proved that differences of skull shapes are related to age, gender, and ethnicity. In our research, the identification of the sphenoid sinus type was based on Ossama and Guldner classification, which identifies four types of SS, according to the shape and pneumatization degree: type I is conchal, type II is presellar, type III is sellar, and type IV is postsellar. In his research B. Anusha found that type III was predominant with $93 \%$, it was followed by type II with $6.7 \%$, and at last, very rare type I is $0 \%$. B. Anusha's results were confirmed in our research as the following: $47 \%, 15 \%, 0 \%$, respectively. Type III of sphenoid sinus structure prevails in the general population among males and is about $62 \%$, and type IV prevails in females with $48 \%$. Mesocranic males of types II and III dominated with $80 \%$ and $62 \%$, respectively, and most brachycranic females were of type II with 61.5\%. Similarly, there were no cases with type I (Conchal) of pneumatization in Azadeh Rahmati's study, 2016 [27], with 103 patients, but 2 cases (1.9\%) of type II (Presellar), 15 cases (14.6\%) of type III (Sellar), and 86 cases (83.5\%) of type IV (Postsellar) were identified. Type IV was more common among 
males than females. In our research, type IV is 52\% among 40-60 years aged females. Senja Tomovic's research [28] is considered unique because patients were grouped by gender and different ethnic groups. The overall distribution of sphenoid sinus pneumatization was as the following: $1.8 \%$ of Conchal, $7.3 \%$ of Presellar, $47.6 \%$ of Sellar, and $43.3 \%$ of Postsellar. The analysis by gender and ethnicity (African American, Latin American, Caucasian, Asian) showed that males of type III and IV were $36.2 \%$ each, and females had a predominance of $48 \%$. However, there were no statistical differences in gender, age, or ethnicity between the groups ( $p>0.05$ ). In our research, 60-80 years aged females had type III of $S S$, which is 2 times more than males of the same age category. It is assumed that the sphenoid sinus width increases with age. However, the data we've obtained does not match the research of Yonetsu et al., 2000 [29], proving the opposite. Type I is rare and usually present in young people, because their pneumatization process may be incomplete, but ethnicity and sample size may also play an important role. It is considered that sphenoid sinus of type I to be the most in children because sphenoid sinus pneumatization begins from 6 months to 4 years and ends by 14-18 years. There is no type I in our research $(0 \%)$, which is more consistent with the data reported before. During type I surgery, EETSA (endoscopic endonasal transsphenoidal approach) adaptation is necessary, this increases its complexity due to bone thickness between the anterior wall of sphenoid bone and SS. There is no sellar bulge in type II because the sinus extends only to the plane perpendicular to the sella turcica front face. The sellar bulge serves as an important landmark that facilitates surgical access. On the contrary, there are optimal conditions for transsphenoidal pituitary surgery when sphenoid sinus is of type IV. However, a highly pneumatized sphenoid sinus may also lead to mistakes, distorting anatomical configuration of the sphenoid bone body, increasing the risk of accidental perforation and damage of ICA and ON. And extensive pneumatization in the back of sella turcica or clivus can lead to postoperative leakage of liquor. The most vulnerable structures along the sinus are ICA at sella turcica anterior wall and ON located superolateral. Neşe Asal (2018) [30] retrospectively investigated the interconnection between sphenoid sinus, carotid canal, and visual canal using paranasal sinus computed tomography (PNSCT) of 300 patients with 159 male and 141 female. In his work, ICA canal protrusion was $23.9-32.1 \%$ in males and 35.5-36.2\% in females. The absence of ICA canal protrusion was detected more often in females (34\%) than in males (22\%). Protrusion of ON canal was $33.3 \%$ and $30.5 \%$ in males and females, respectively. Type 4 of optic canal location, i.e. deviation to sphenoid sinus laterally and posterior to the latticed bone, was found in both genders. The absence of ON canal protrusion was found in $11.3 \%$ of males and $9.9 \%$ of females. The most common type of ICA canal location in females was type 3, i.e. bilateral protrusion into sphenoid sinus wall, and type 1 of ipsilateral $\mathrm{ON}$ canal location, i.e. without protrusion into the sinus. Elderly patients have more wide canals, with no irregularities of the sinus walls. The international averages of ICA dehiscence range from 1.5 to $30.0 \%$. The international average values of ON dehiscence range from 4.1 to $35.6 \%$. Daniele Gibelli's classification, 2019, taken as a basis in our research showed that ICA canal forms a protrusion on sphenoid sinus lateral wall inner surface in $60 \%$ of $60-80$ years aged females. The absence of ON and ICA protrusions was detected in $80 \%$ of $60-80$ years old males. The ON canal causes an indentation on sphenoid sinus wall in $49 \%$ of $20-40$ years old females. Based on sphenoid bone anatomical structure, it is obvious that the optic canal can form a bulge in the sphenoid sinus wall only in cases of the latter spreading to the small wing root and further up to the anterior 
sphenoid process. That is, in these cases, the so-called upper lateral pocket of sphenoid sinus is formed, and canal protrusion degree into the sinus depends on its pneumatization. If the surgeon is not aware of the ICA position, it can cause lethal bleeding during surgery, because it is impossible to control ICA bleeding inside SS. In addition, it is necessary to keep in mind neurological complications, which are also inevitable. Sphenoiditis can make greater the artery wall vulnerability of a degenerative nature or protrusion. The risk of blindness is high for $\mathrm{ON}$ damages inside the sinus.

Thus, careful planning of trans-sphenoid access to the sella is possible with modern imaging methods. Different anatomical variations can be detected so that problems can be predicted to be assessable. In order to avoid morbid consequences during surgery, it is imperative that clinicians determine the location and extent of sphenoid sinus walls and its relation to adjacent vital structures whenever trans-sphenoid pituitary surgery is expected. The few surgical tips related to sphenoid sinus anatomical configuration are important to keep in mind during such an approach.

\section{Materials And Methods}

The retrospective research, using magnetic resonance imaging (MRI) scans of head, included 1111 people, with 410 males and 701 females out of them but the scope of the article is limited to 93 of them, including 34 males (37\%) and 59 females (63\%) aged from 20 to 71 years. The research design complies with the Helsinki Declaration's provisions and was approved by the Local Ethics Committee of the West Kazakhstan Medical University named after Marat Ospanov №50 from January 17, 2020. The average age of males was 41.6 (20-71 years), and for females was 41.7 (20-66 years).

Inclusion criteria were as the following: 1) age range from 20 to 71 years, 2) patients living in Aktobe region, 3) patients sent for examination with pituitary (hypophysis) pathology, 5) patients referred with CSR vascular pathology, 6) patients referred for verification of CSR pathology diagnosis.

Exclusion criteria were as the following: 1) patients with skull bones fractures, 2) patients after skull trepanation, 3) patients having orthodontic and orthognathic research at examination time, 4) patients with congenital skull malformations, having gross skull deformation, 5) patients with brain tumors and hemorrhages with obvious CSR compression at examination time, 6) pregnancy, lactation, long-term use of hormonal drugs by persons of both gender.

MRI images were taken from the Department of magnetic resonance imaging in Aktobe, after receiving the chief doctor's informed consent. Scans were performed using Centricity Enterprise ${ }^{\mathrm{TM}}$ (PACS) image archiving and transfer systems on Toshiba Vantage Titan 1.5 (Japan) with $0.5 \mathrm{~mm}$ slice thickness. Craniological parameters such as transverse-longitudinal skull index, sphenoid sinus pneumatization type, protrusion and/or dehiscence of ICA and ON canals were measured using RadiAnt Dicom Viewer 5.5.1 software.

Craniometric examination included determining longitudinal and transverse skull dimensions. According to the research of D. A. Domenyuk (2019) [15], transverse-longitudinal skull index was measured in two 
mutually perpendicular planes. The head length was measured in the median sagittal plane (head longitudinal diameter), the head width was measured in the frontal (orbital) plane (transverse diameter of the head). The head shape was determined by the cranial (head) index (Cl) calculated as a percentage ratio of the transverse head diameter (between Aurion points) to the longitudinal head diameter (from glabella point to opisthocranion point) according to the classification of R. Martin (1928). As per the research results, the following skull forms were identified: dolichocrane - long skull (cranial index is from 70 to 74,9 ), brachycrane - wide skull (cranial index is 80 or more), and mesocran - medium form (cranial index is from 75 to 79,9 ).

The classifications Ossama [16] and Guldner [17] (2012) were used to identify sphenoid sinus type. There are four types of SS, reflecting their shape and pneumatization degree: type I - conchal, type II - presellar, type III - sellar, and type IV - postsellar (Fig. 5). All images were divided into four groups according to ICA and/or ON protrusion into SS: no protrusion of any structure (group 1), ICA protrusion only (group 2), ON protrusion only the (group 3), protrusion of both ICA and ON (group 4), based on the research by Daniele Gibelli, 2019 [18].

To maintain the accuracy of the research, we divided all patients by gender into 3 age groups: $20-$ 40 years old, 41-60 years old, and over 60 years old, similar to Seizo Yamashita's research [19]. However some authors, for example, B. Anusha et al., 2015, [20] included patients starting from 18 years old into the research scope, and Davudi et al. [21] as well as Heiwaidi et al. [22] expanded their researches starting from 16 years aged patients.

\section{Statistical analysis.}

Input, accumulation, storage and primary sorting of research data were performed using a program Microsoft Excel and Statistica 8.0.

The Pearson's $\mathrm{X}^{2}$-correlation test was used to hypothesis concerning patients age and pneumatization type, and patients age and protrusion and/or dehiscence of ICA and ON canals.

$\mathrm{P}<0.05$ was considered as statistically significant level.

The Cramer's V criterion was applied for multiple tables.

\section{Declarations}

\section{Acknowledgments}

The authors would like to gratefully acknowledge the technical support and for assistance in processing MRI data of Mr Arystan Izteleuov, radiologist assistant, from the MRI division of the hospital. I would like to thank Mrs Zhanylsyn Gaisiyeva, research management department researcher, biostatistics sector of university ZKMU named after M. Ospanova for assistance and advice in statistical data processing. 
Merey B. Aliyeva $\mathrm{PhD}^{1}$ - Data collection and manuscript writing.

Mahmoud Farid Mahrous Bathalla MD² - editing.

Aru B. Balmagambetova $\mathrm{PhD}^{1}$ - Data analysis.

Gulmira A. Zhurabekova $\mathrm{MD}^{1}$ - project development and management.

All authors have read and approved the manuscript.

\section{FUNDING}

The authors have no financial or personal relationship with any third party whose interests could be positively or negatively influenced by the article's content. This research did not receive any specific grant from funding agencies in the public, commercial, or not-for-profit sectors.

\section{Informed consent}

Informed consent "Consent to the processing of personal data" was obtained from the chief physician of the hospital for the collection and processing of MRI of the head of patients who were examined in 2019. Personal data refers to the full name, gender, date of birth, physiological characteristics of the individual, its external parameters).

\section{COMPLIANCE WITH ETHICAL STANDARDS}

Conflict of interest: The authors declare that they have no competing interests.

\section{References}

1. Little AS, Kelly D, Milligan J, et al. Predictors of sinonasal quality of life and nasal morbidity after fully endoscopic transsphenoidal surgery. J Neurosurg 122: 1458-65. https:// doi: 10.3171/2014.10.JNS141624 (2015).

2. Guldner C, Pistorius SM, Diogo I, Bien S, Sesterhenn A, Werner J.A. Analysis of pneumatisation and neurovascular structures of the sphenoid sinus using cone-beam tomography (CBT). Acta Radiol 1;53(2):214-219. https://doi: 10.1258/ar.2011.110381 (2012).

3. Laury AM, Oyesiku NM, Hadjipanayis CG, Delgaudio JM, Wise SK. Incidental sinonasal findings identified during preoperative evaluation for endoscopic transsphenoidal approaches. Am J Rhinol Allergy;27(3):202-205. https://doi: 10.2500/ajra.2013.27.3871 (2013).

4. Romero $A D C B$, Barkhoudarian G, Silva CE, Aguiar PHP, Jr ERL. The variations in anatomy of the sphenoid sinus and sellar floor to perform transsphenoidal endoscopy in adult age: a literature 
review. J Bras Neurohcirurg 23(1):11-17 (2012).

5. Stokovic N, Trkulja V, Dumic-Cule I, Cukovic-Bagic I, Lauc T, Vukicevic S, Grgurevic L. Sphenoid sinus types, dimensions and relationship with surrounding structures. Ann Anat 203:69-76. https://doi: 10.1016/j.aanat.2015.02.013 (2016).

6. Cho J H, Kim J K, Lee J G, Yoon J H. Sphenoid sinus pneumatization and its relation to bulging of surrounding neurovascular structures. Ann Otol Rhinol Laryngol 119(9):646-650. https://doi: 10.1177/000348941011900914 (2010).

7. Fernandez-Miranda JC, Prevedello DM, Madhok R, et al. Sphenoid septations and their relationship with internal carotid arteries: anatomical and radiological study. Laryngoscope 119: 1893-6. https://doi: 10.1002/lary.20623 (2009).

8. Rahmati A, Ghafari R, AnjomShoa M. Normal variations of sphenoid sinus and the adjacent structures detected in cone beam computed tomography. J Dent (Shiraz) 17(1):32-37. PMCID: PMC4771050 (2016).

9. Cavallo LM, Messin AA, Cappabianca P, Esposito F, Divitus E, Gardner P, Tascha BM. Endoscopic endonasal surgery of the midline skull base: anatomical study and clinical considerations. Neurosurgery Focus 19(1):E2;1-4. https://doi.org/10.3171/foc.2005.19.1.3 (2005).

10. Balasubramanian Anusha. Anatomical variants of surgically important landmarks in the sphenoid sinus: a radiologic study in Southeast Asian patients. Surg Radiol Anat 37(10):1183-90. https://doi: 10.1007/s00276-015-1494-8 (2015).

11. Sofferman RA, Harris P. Mosher Award thesis. The recovery potential of the optic nerve. Laryngoscope 105 (7 Pt 3 Suppl 72):1-38 PMID: 7603288 (1995).

12. Sirikci A, Bayazit YA, Bayram M, Mumbuç S, Güngör K, Kanlikama M. Variations of sphenoid and related structures. Eur Radiol 10(5):844-848. https://doi: 10.1007/s003300051016 (2000).

13. Carrabba G, Locatelli M, Mattei L, Guastella C, Mantovani G, Rampini P, Gaini SM. Transsphenoidal surgery in acromegalic patients: anatomical considerations and potential pitfalls. Acta Neurochir. (Wien) 155:125-130. https://doi: 10.1007/s00701-012-1527-6 (2013).

14. Kazkayasi M, Karadeniz Y, Arikan OK. Anatomic variations of the sphenoid sinus on computed tomography. Rhinology 43:109-114 PMID: 16008065 (2005).

15. Domenyuk D.A. Diagnostic opportunities of cone-box computer tomography in conducting craniomorphological and craniometric research in assessment of individual anatomical variability. Part II, Institute of Dentistry No. 1 (82); 72-76. (Russian journal) (2019).

16. Hamid O, El Fiky L, Hassan O, Kotb A, El Fiky S. Anatomic Variations of the Sphenoid Sinus and Their Impact on Trans-sphenoid Pituitary Surgery. Skull Base 18:9-15. https://doi: 10.1055/s-2007992764. ISSN 1531-5010 (2008).

17. Güldner C, Pistorius SM, Diogo I, Bien S, Sesterhenn A, Werner JA. Analysis of pneumatization and neurovascular structures of the sphenoid sinus using cone-beam tomography (CBT) Acta Radiol 53:214-219. https://doi: 10.1258/ar.2011.110381 (2012). 
18. Daniele Gibelli et al. Relationship between sphenoid sinus volume and protrusion of internal carotid artery and optic nerve: a 3D segmentation study on maxillofacial CT-scans. Surg Radiol Anat 41(5):507-512. https://doi: 10.1007/s00276-019-02207-w (2019).

19. Seizo Yamashita et al. A radiologic morphometric study of sellar, infrassellar and parasellar regions by magnetic resonance in adults. Springerplus 3:291. https://doi: 10.1186/2193-1801-3-291 (2014).

20. Anusha, A. Baharudin, R.Philip, S.Harvinder, B. Mohd Shaffie, R.Ramiza Anatomical variants of surgically important landmarks in the sphenoid sinus: a radiologic study in Southeast Asian patients. Surg Radiol Anat 37(10):1183-90. https://doi: 10.1007/s00276-015-1494-8 (2015).

21. Davoodi M, Saki N, Saki G et al. Anatomical variations of neurovascular structures adjacent sphenoid sinus by using CT scan. Pak J Biol Sci 12:522-525. https://doi:

10.3923/pjbs.2009.522.525 (2009).

22. Hewaidi G, Omami G. Anatomic variation of sphenoid sinus and related structures in Libyan population: CT scan study. Libyan J Med 1;3(3):128-133. https://doi: 10.4176/080307 (2008).

23. Scuderi AJ, Harnsberger HR, Boyer RS. Pneumatization of the paranasal sinuses: normal features of importance to the accurate interpretation of CT scans and MR images. AJR Am J Roentgenol. 60:1101-1104. https://doi: 10.2214/ajr.160.5.8470585 (1993).

24. Speransky B.C. Fundamentals of medical craniology, Moscow: Meditsina, 1988, 288 p.

25. Pavlov, A. V. Age-related features of head shape according to the long-latitude index of males and females. / A.V. Pavlov // Morphological Bulletin No. 1-2. - Moscow-Berlin, Appendix No. 1. - Pp. 230231. (2006).

26. Hammer G, Radberg C. The sphenoidal sinus: An anatomical and roentgenologic study with reference to transsphenoid hypophysectomy. Acta Radiol 56:401-422. https://doi.org/10.1177/028418516105600601 (1961).

27. Azadeh Rahmati et al. Normal Variations of Sphenoid Sinus and the Adjacent Structures Detected in Cone Beam Computed Tomography. J Dent (Shiraz) 17(1): 32-37 PMID: 26966706 (2016).

28. Senja Tomovic et al. High-Resolution Computed Tomography Analysis of Variations of the Sphenoid Sinus. J Neurol Surg B Skull Base 74(2):82-90. https://doi: 10.1055/s-0033-1333619 (2013).

29. Yonetsu, K., Watanabe, M. \& Nakamura, T. Age-related expansion and reduction in aeration of the sphenoid sinus: volume assessment by helical CT scanning. AJNR Am. J. Neuroradiol 21(1):179-82. PMID: 10669247 (2000).

30. Neşe Asal et al. Carotid canal and optic canal at sphenoid sinus. Neurosurg Rev. 42 (2):519-529. https://doi: 10.1007/s10143-018-0995-4. (2019).

\section{Figures}



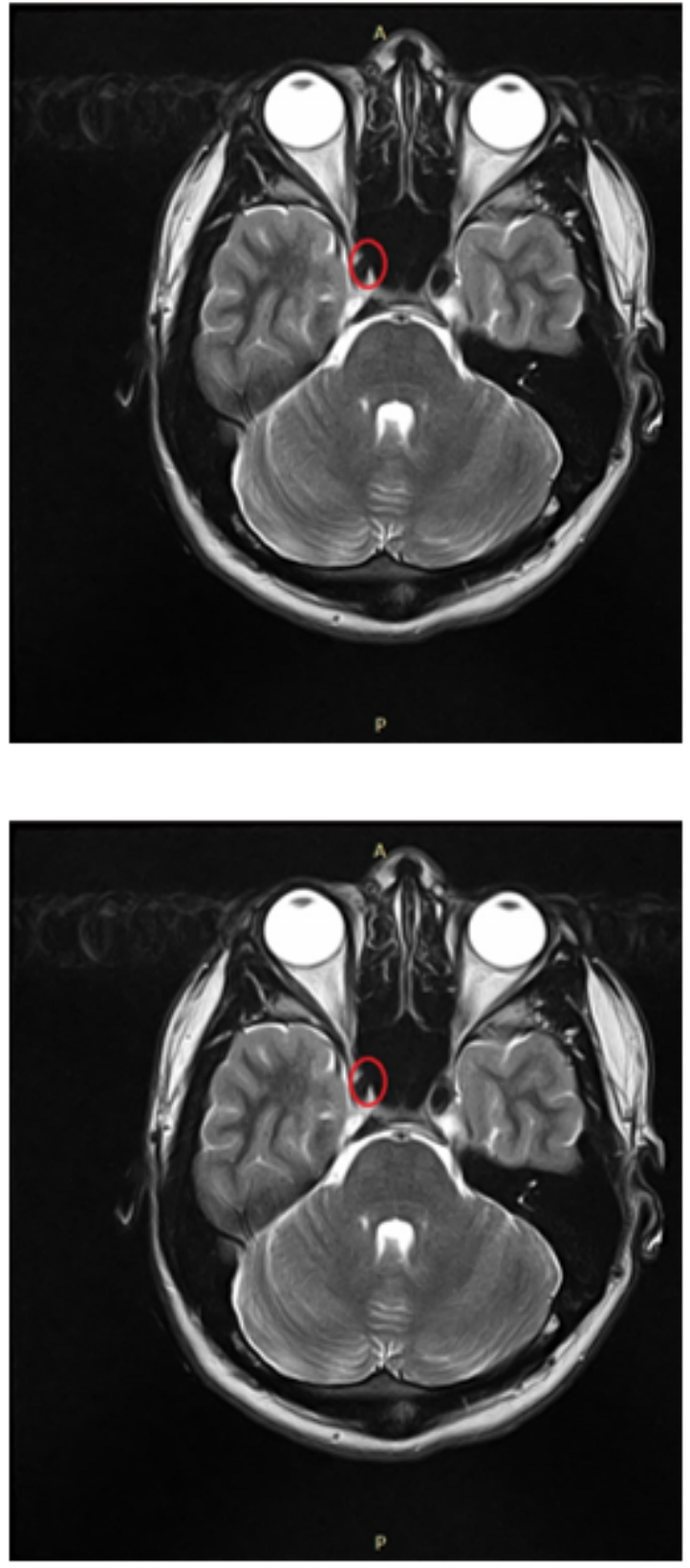

Figure 1

a) Internal carotid artery dehiscence (horizontal plane), right side. b) Internal carotid artery dehiscence (horizontal plane), right side. 


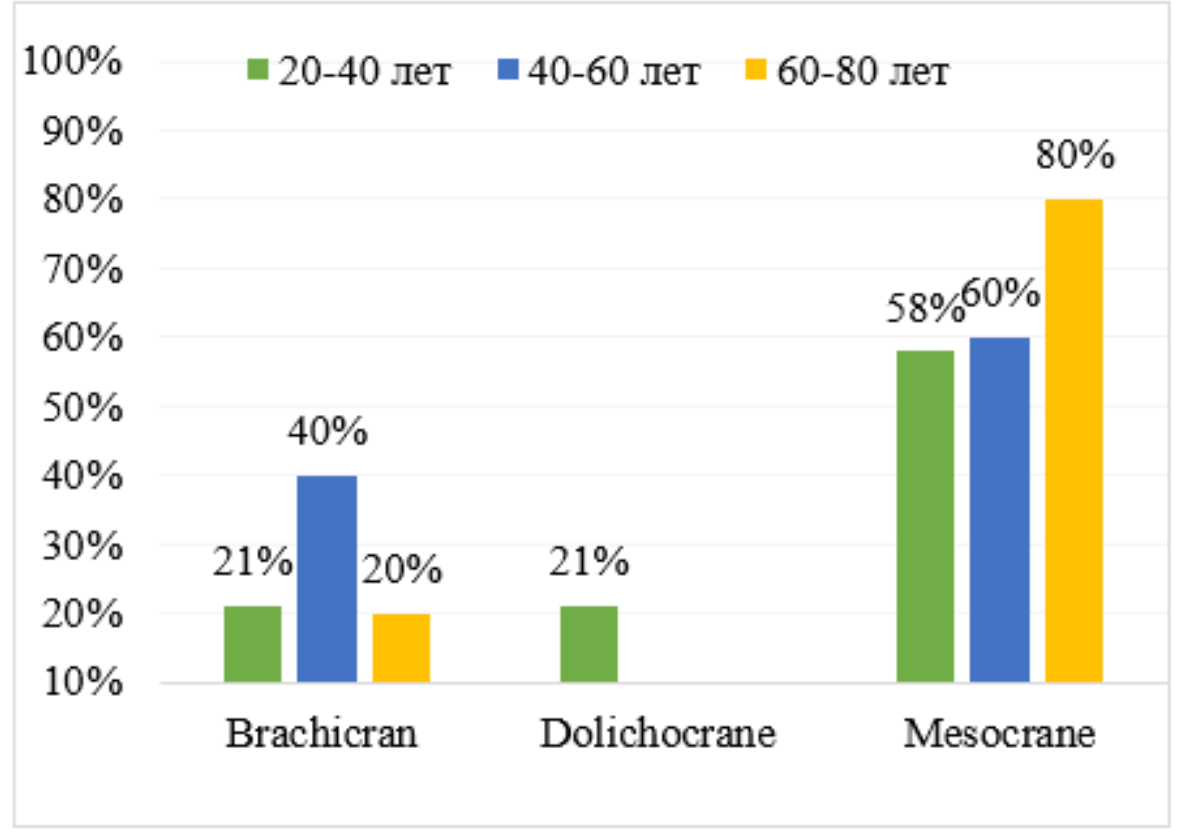

\section{Figure 2}

Percentage of male skull structure types.

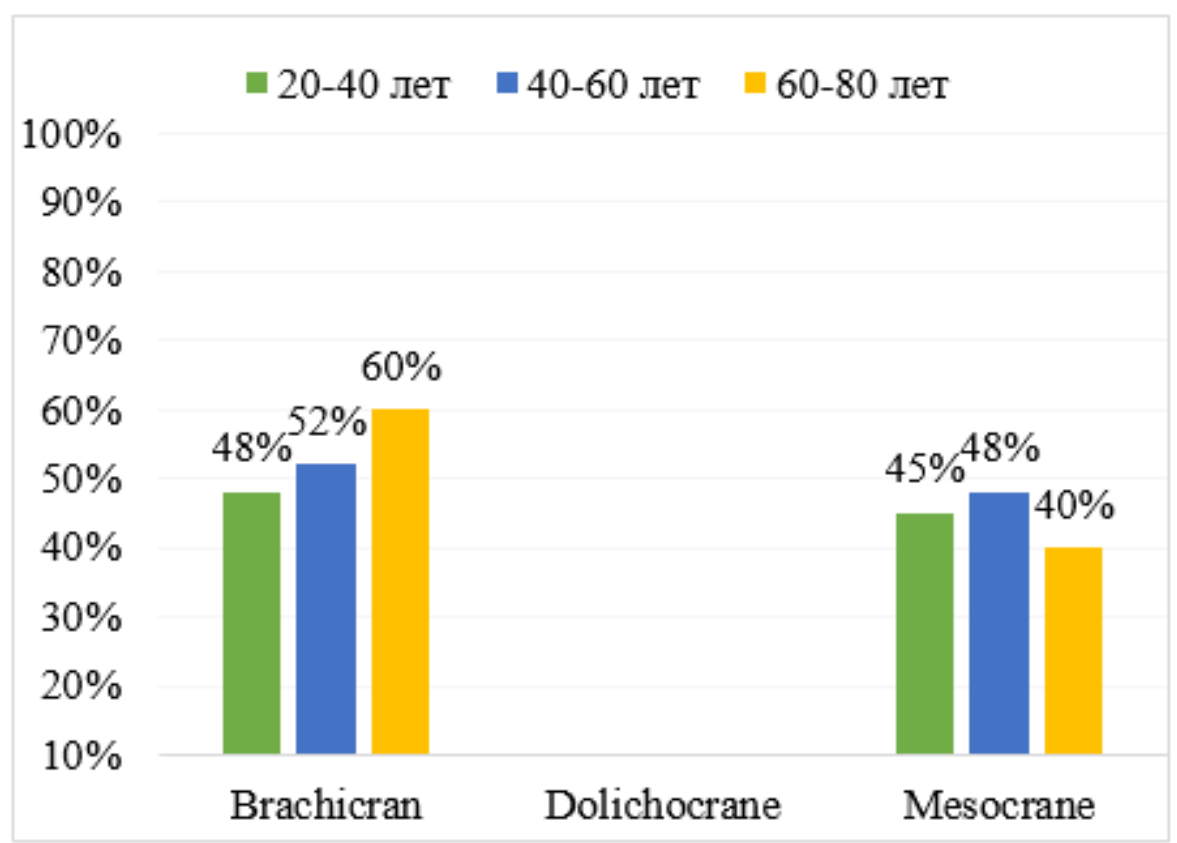

Figure 3

Percentage of female skull structure types. 


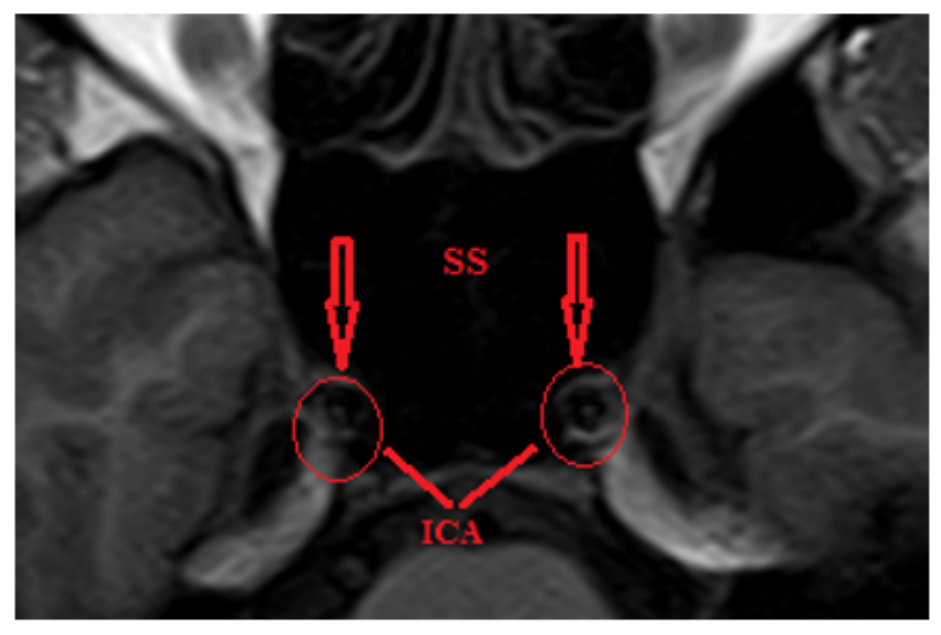

a

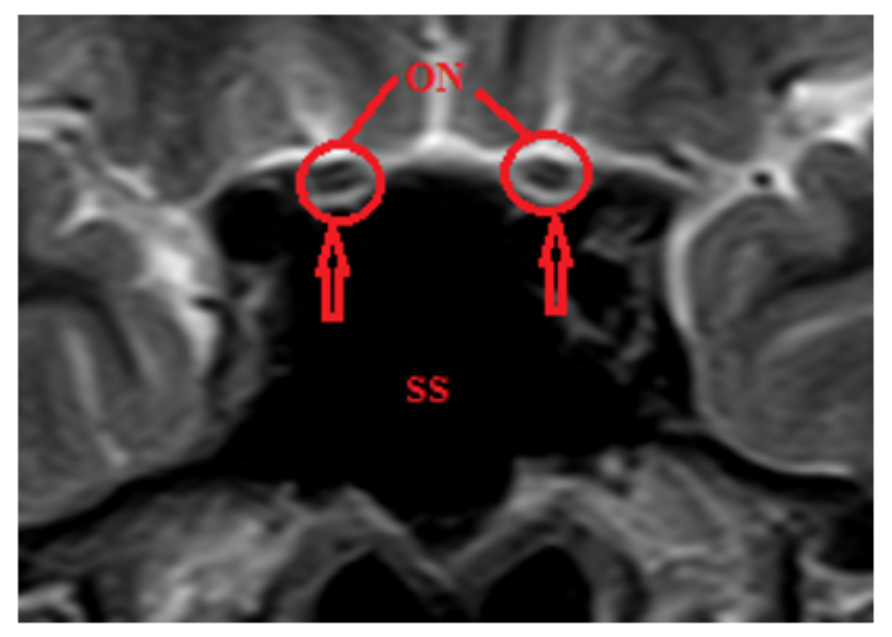

b

Figure 4

a) Internal carotid arteries protrusion (horizontal plane) b) Optical nerve protrusion (horizontal plane)

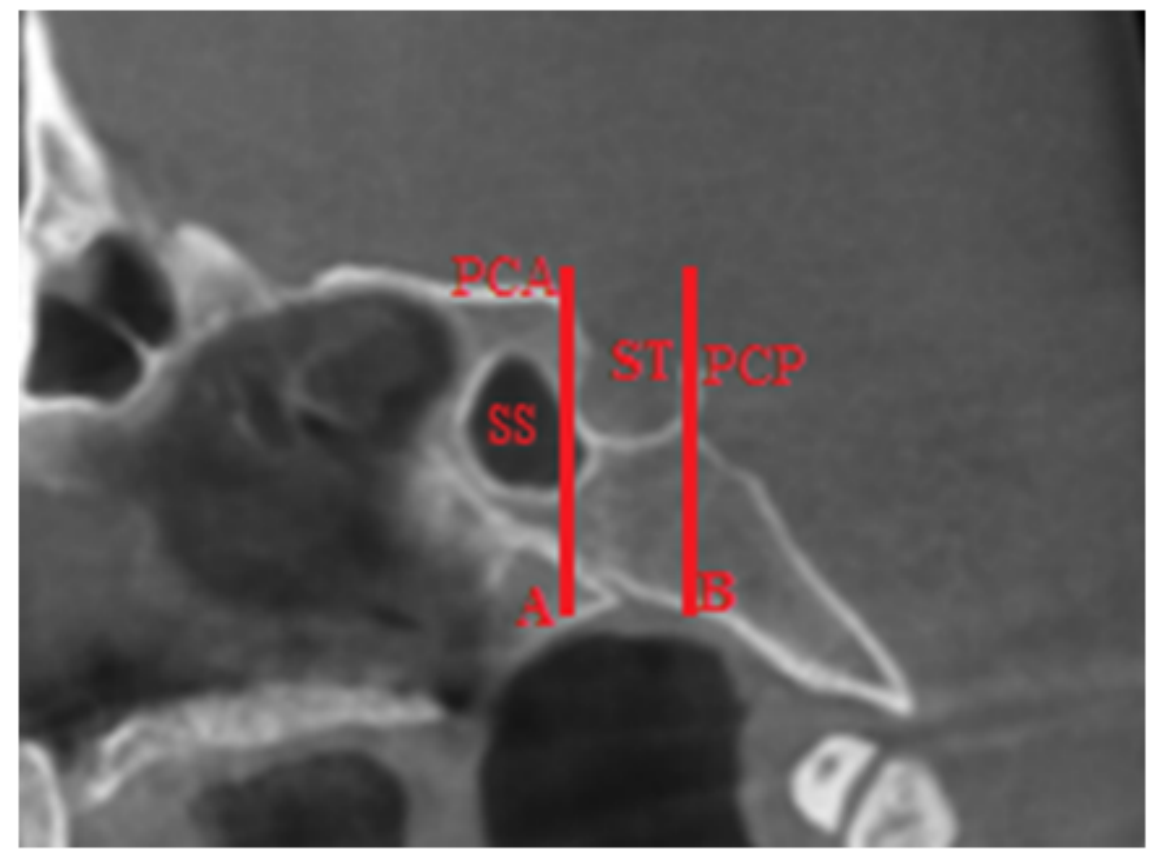

Figure 5

Relation of sphenoid sinus to the sella turcica (sagittal section of the sphenoid bone) A - line perpendicular to anterior sphenoid process; $B$ - line perpendicular to posterior sphenoid process; PCA processus clinoid anterior; PCP - processus clinoid posterior; ST - sella tucica; SS - sphenoid sinus.

\section{Supplementary Files}

This is a list of supplementary files associated with this preprint. Click to download. 
- SupplementaryDatasetfilesMerey.docx

Page 15/15 